\title{
Simulation of Reaction-Induced Phase Separation in Surface Alloy
}

\author{
G. ZVEJNIEKS ${ }^{a, b}$ AND E.E. TORNAU ${ }^{c}$ \\ ${ }^{a}$ Department of Physics, University of Latvia \\ Raina 19, LV-1586, Riga, Latvia \\ ${ }^{b}$ Institute for Solid State Physics \\ Kengaraga 8, LV-1063, Riga, Latvia \\ ${ }^{c}$ Semiconductor Physics Institute \\ Goštauto 11, LT-01108, Vilnius, Lithuania
}

\begin{abstract}
Using kinetic Monte Carlo method we simulate the dynamics of biatomic $\mathrm{Au}_{0.3} \mathrm{Ni}_{0.7}$ surface alloy separation on $\mathrm{Ni}(111)$ due to $\mathrm{Ni}(\mathrm{CO})_{4}$ out-reaction. The experiment of Vestergaard et al. is modeled by counterbalancing dynamical processes and interactions between reactants. The simulations demonstrate step flow rate increase with $\mathrm{CO}$ coverage, $c_{\mathrm{CO}}$, in qualitative agreement with the experiment only for $c_{\mathrm{CO}} \lesssim 0.45$ monolayer. Moreover, we demonstrate both $\mathrm{CO}$ influence on reaction process and $\mathrm{Au}$ domain formation.
\end{abstract}

PACS numbers: 68.43.Fg, 68.43.Hn, 68.43Mn, 64.60.Cn

\section{Introduction}

Bimetallic catalysts can have radically different properties as compared to those observed for their constituents. Up to now the main focus has been on bimetallic systems that form thermodynamically stable alloys in the bulk. Recent advances in surface growth technologies allowed to fabricate surface alloys, which are formed out of two thermodynamically bulk-immiscible metals only in the surface layer. The Au-Ni surface alloy on $\mathrm{Ni}(111)$ is one of such novel catalysts with improved properties in activity and selectivity. However, it was unstable at industrially relevant high $\mathrm{CO}$ pressures due to $\mathrm{Ni}(\mathrm{CO})_{4}$ formation reaction [1].

The kinetic Monte Carlo (MC) modeling of experimentally observed $\mathrm{Au}-\mathrm{Ni}$ separation in $\mathrm{Au} / \mathrm{Ni}(111)$ surface alloy was started in [2] by neglecting the role of $\mathrm{CO}$. Here we demonstrate qualitatively the most general trends of the separation dynamics: (i) step flow rate (reaction front) dependence on $\mathrm{CO}$ coverage (i.e., pressure) and (ii) Au islands growth dependence on reactant mobility.

\section{Simulation model and parameters}

Computer simulations are performed at room temperature on a hexagonal lattice of size $128 \times 128$ in the units of lattice constant, $a_{0}$, with periodic boundary 
conditions. Three types of reactants corresponding to $\mathrm{CO}, \mathrm{Au}$, and $\mathrm{Ni}$ are considered. Initially lattice is covered with $30 \%$ of $\mathrm{Au}$ and $70 \%$ of $\mathrm{Ni}$ atoms randomly as in experiment [1] with two steps created by removing $\mathrm{Au}$ and $\mathrm{Ni}$ atoms from twelve rows in the middle of the lattice. To meet the observation [2] that $\mathrm{Au}$ coverage on step ridges is close to unity, we replace Ni step atoms by Au. The MC simulations are performed exploiting the standard model and pair algorithm [3] with the following processes.

(i) Adsorption of $\mathrm{CO}$ from gas phase to both empty lattice sites and atop $\mathrm{Ni}$ atoms is assumed as non-activated. In this case the adsorption rate at experimental conditions $\left(p_{\mathrm{CO}}=10-60\right.$ Torr $)$ could be estimated from the collision theory as $k_{\mathrm{a}}=(2-12) \times 10^{6} \mathrm{~s}^{-1}$.

(ii) Desorption rate of $\mathrm{CO} k_{\mathrm{d}}=1.1 \times 10^{-7}$ is found from equation $k_{\mathrm{d}}=$ $k_{0}^{\mathrm{d}} \exp \left(-E_{\mathrm{d}} / k_{\mathrm{B}} T\right)$ with the pre-factor $k_{0}^{\mathrm{d}}=10^{13} \mathrm{~s}^{-1}$ and activation energy $E_{\mathrm{d}}=$ $1.18 \mathrm{eV}$ for $\mathrm{Ni}(111)$ surface in the absence of $\mathrm{Au}$ [4].

(iii) Only $\mathrm{Au}$ atoms can perform activated jumps to the nearest neighbor (NN) empty lattice sites, while $\mathrm{CO}$ and $\mathrm{Ni}$ are immobile. The estimate of activation barrier for $\mathrm{Au}$ diffusion is $E_{\mathrm{a}}^{\mathrm{Au}}=0.53 \mathrm{eV}$ [5]. Thus, at room temperature the experimental jump rate is $\nu^{\mathrm{Au}}=1.1 \times 10^{4} \mathrm{~s}^{-1}$, where we have chosen a pre-factor $\nu_{0}^{\mathrm{Au}}=10^{13} \mathrm{~s}^{-1}$.

(iv) Formation of $\mathrm{Ni}(\mathrm{CO})_{2}$ occurs with reaction rate $k_{\mathrm{r}}$, when a $\mathrm{Ni}$ atom with atop $\mathrm{CO}$ reactant has both another $\mathrm{CO}$ and $\mathrm{Au}$ atom in $\mathrm{NN}$ positions and the total number of its $\mathrm{NN} \mathrm{Au}$ and $\mathrm{Ni}$ atoms is less than five (border, kink or corner site). Since $\mathrm{Ni}(\mathrm{CO})_{2}$ formation is rate limiting step in $\mathrm{Ni}(\mathrm{CO})_{4}$ formation [6], we assume that $\mathrm{Ni}(\mathrm{CO})_{2}$ leaves the surface instantly.

These estimates indicate that $\mathrm{MC}$ simulations with experimental rates $\nu^{\mathrm{Au}}$, $k_{\mathrm{a}}$, and $k_{\mathrm{d}}$ are unrealistic for today's computing facilities. Therefore a reduction of rates is required, while keeping the experimental rate inequalities $k_{\mathrm{d}} \ll \nu^{\mathrm{Au}}<k_{\mathrm{a}}$ valid. In all simulations we fix both $\mathrm{CO}$ adsorption rate $k_{\mathrm{a}}=4 \times 10^{3} \mathrm{~s}^{-1}$ and reaction rate $k_{\mathrm{r}}=10 \mathrm{~s}^{-1}$. At the same time we consider different Au diffusion $\left(19\right.$ and $\left.1900 \mathrm{~s}^{-1}\right)$ and CO desorption rates $\left(2 \times 10^{-11}-6 \times 10^{-3} \mathrm{~s}^{-1}\right)$ as sensitive parameters, which allow us to manipulate Au cluster growth and $\mathrm{CO}$ surface coverage, respectively. Thus we assume that $k_{\mathrm{d}}$ plays a role of pressure in our model.

Adsorption and desorption rates of $\mathrm{CO}$ are modified by $\mathrm{CO}-\mathrm{CO}$ and $\mathrm{CO}-\mathrm{Au}$ NN interactions [3]. Since these interactions are unknown, as a starting guess we set them repulsive and equal to $v_{\mathrm{CO}-\mathrm{CO}}=0.16 \mathrm{eV}$ and $v_{\mathrm{Au}-\mathrm{CO}}=0.08 \mathrm{eV}$ in all simulations. For simplicity the attraction between $\mathrm{Au}-\mathrm{Au}$ and $\mathrm{Ni}-\mathrm{Au}$ is set equal: $v_{\mathrm{Au}-\mathrm{Au}}=v_{\mathrm{Au}-\mathrm{Ni}}$.

\section{Results}

A fixed desorption rate, $k_{\mathrm{d}}$, leads to a saturated $\mathrm{CO}$ surface coverage, $c_{\mathrm{CO}}$, which establishes after $\mathrm{Ni}$ removal and Au cluster formation, see inset of Fig. 1a. 
Thus, we obtain a time dependence of $\mathrm{Ni}$ surface coverage, $c_{\mathrm{Ni}}$, on $c_{\mathrm{CO}}$ by a subsequent change of $k_{\mathrm{d}}$, Fig. 1a. For $c_{\mathrm{CO}} \lesssim 0.45\left(k_{\mathrm{d}}<3.5 \times 10^{-7} \mathrm{~s}^{-1}\right)$ we observe an increase in $\mathrm{Ni}$ removal rate with increase in $c_{\mathrm{CO}}$, since $\mathrm{CO}$ molecules adsorbed from a gas phase readily participate in carbonyl formation reaction. $\mathrm{Ni}$ removal rate reaches maximum at about $c_{\mathrm{CO}} \approx 0.45$ and further it decreases with increase in $c_{\mathrm{CO}}$, since adsorbed $\mathrm{CO}$ molecules start to hinder $\mathrm{Au}$ diffusion thus blocking the reaction.
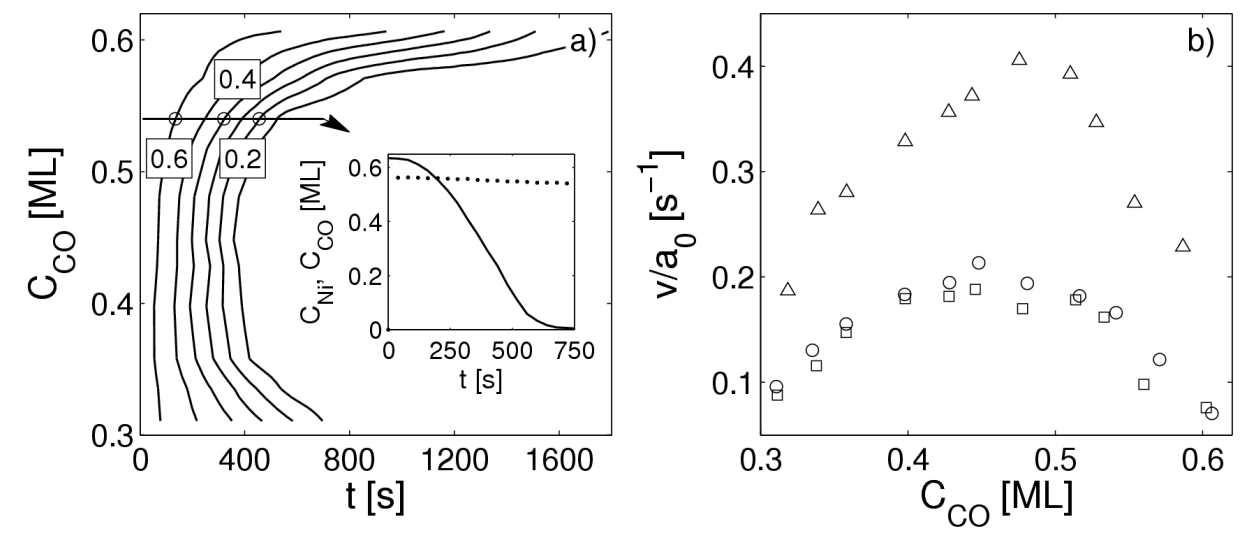

Fig. 1. (a) Contour plot of $\mathrm{Ni}$ coverage (given in boxes) time dependence on $c_{\mathrm{CO}}$. Parameters: $\nu^{\mathrm{Au}}=19 \mathrm{~s}^{-1}, v_{\mathrm{Au}-\mathrm{Au}}=-0.05 \mathrm{eV}$. Solid and dotted lines in the inset correspond to $\mathrm{Ni}$ and $\mathrm{CO}$ coverage, respectively, at $k_{\mathrm{d}}=10^{-9} \mathrm{~s}^{-1}$. (b) Step flow rate dependence on $\mathrm{CO}$ concentration (i) circles — as in case (a), (ii) triangles $\nu^{\mathrm{Au}}=1900 \mathrm{~s}^{-1}$, and (iii) squares $-\nu^{\mathrm{Au}}=1900 \mathrm{~s}^{-1}, v_{\mathrm{Au}-\mathrm{Au}}=-0.075 \mathrm{eV}$.

The gradient of $\mathrm{Ni}$ coverage time dependence leads to step-flow rate, v, Fig. 1b, which can be compared with experiment [1]. An increase in v with $c_{\mathrm{CO}}$ agrees well with the experiment and is rather insensitive to the change of simulation parameters. However, the following decrease is the artefact of the simplifications made in our model. We assume that CO can occupy fcc lattice sites and, despite mutual repulsion, two $\mathrm{CO}$ molecules can be $\mathrm{NN}$, contrary to indications [7] of a a strong $\mathrm{CO}-\mathrm{CO}$ NN repulsion and occupation of bridge and top sites at high $\mathrm{CO}$ coverage. The rise of $\mathrm{Au}$ hopping rate by two orders expands the step flow rate growth region up to $c_{\mathrm{CO}} \approx 0.5$ and twice increases v, Fig. 1b. Contrary, an increase by 1.5 times of $\mathrm{Au}-\mathrm{Au}$ (and $\mathrm{Au}-\mathrm{Ni}$ ) interaction in the limit of fast $\mathrm{Au}$ diffusion leads to double reduction of the step flow rate, which now accidentally coincides with the slow Au diffusion case.

A time development of phase separation with $\mathrm{Au}$ islands formation at the wave front is presented in Fig. 2a, b. Let us note that the increase in Au hopping rate, as expected, increases the size of $\mathrm{Au}$ islands, Fig. 2b, c. 


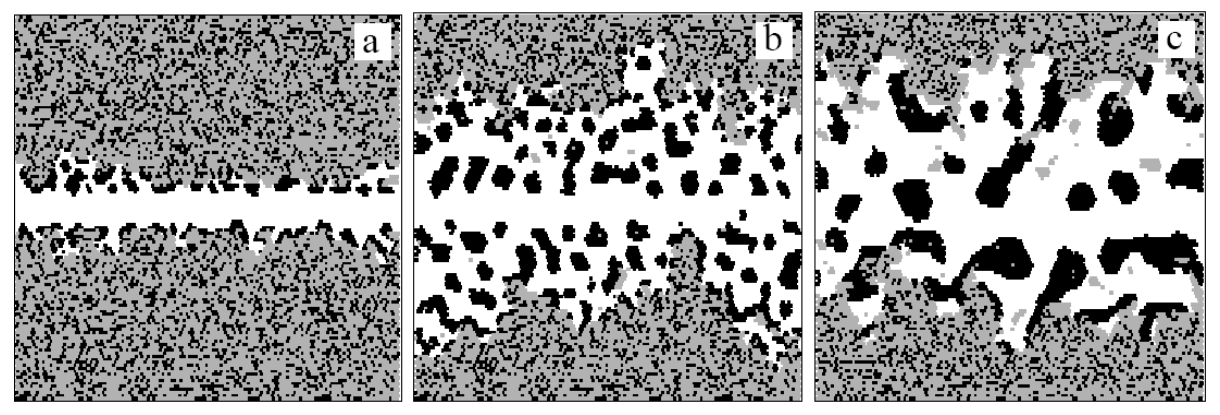

Fig. 2. Snapshots of MC simulations with Au (black) and Ni (gray) reactants. Parameters: $v_{\mathrm{Au}-\mathrm{Au}}=-0.05 \mathrm{eV}, k_{\mathrm{d}}=1.2 \times 10^{-4} \mathrm{~s}^{-1}$. Times from left to right: (a) $60 \mathrm{~s}$, (b) $280 \mathrm{~s}$ at $\nu^{\mathrm{Au}}=19 \mathrm{~s}^{-1}$, and (c) $140 \mathrm{~s}$ at $\nu^{\mathrm{Au}}=1900 \mathrm{~s}^{-1}$.

In summary, we have found the set of kinetic parameters which allows, at least qualitatively within the limits of current computer resources, to explain step flow rate increase with $\mathrm{CO}$ coverage as well as $\mathrm{Au}$ islands formation and ripening process.

\section{Acknowledgments}

This work was supported by LSSSF project MULTIMA (No C-18/2007) and The European Social Fund.

\section{References}

[1] E.K. Vestergaard, R.T. Vang, J. Knudsen, T.M. Pedersen, T. An, E. Lægsgaard, I. Stensgaard, B. Hammer, F. Besenbacher, Phys. Rev. Lett. 95, 126101 (2005). See also: http://www.phys.au.dk/camp/movies/carbonyl.mpg.

[2] V.P. Zhdanov, R.T. Vang, J. Knudsen, E.K. Vestergaard, F. Besenbacher, Surf. Sci. Lett. 600, L260 (2006).

[3] G. Zvejnieks, V.N. Kuzovkov, Phys. Rev. E 63, 051104 (2001).

[4] P.M. Holmblad, J.H. Larsen, I. Chorkendorff, J. Chem. Phys. 104, 7289 (1996).

[5] K. Termentzidis, J. Hafner, F. Mittendorfer, J. Phys., Condens. Matter 18, 10825 (2006).

[6] V.K. Medvedev, R. Börner, N. Kruse, Surf. Sci. 401, L371 (1998).

[7] C. Quiros, O. Robach, H. Isern, P. Ordejon, S. Ferrer, Surf. Sci. 522, 161 (2003). 